See Article page 36.

\section{Commentary: Are platelet patterns repeated in delayed heparin-induced thrombocytopenia/ heparin-induced thrombocytopenia and thrombosis syndrome after cardiac surgery?}

\author{
Robert S. Kramer, MD, ${ }^{a}$ and \\ Timothy E. Hayes, DVM, MD
}

Delayed-onset heparin-induced thrombocytopenia and thrombosis syndrome (HITTS) has been well described. ${ }^{2}$ Awareness of this phenomenon in postoperative cardiac surgery patients is heightened by the case series reported by Catalano and colleagues in this issue of the Journal. ${ }^{3}$ Their retrospective analysis spanned 28 months at a busy cardiac surgery center and included 2496 patients undergoing cardiac surgery with cardiopulmonary bypass (CPB). During that time, 351 patients $(14 \%)$ were readmitted within 30 days, 6 of whom $(1.7 \%)$ were diagnosed with HIT confirmed by both positive heparin-PF4 antibodies (on enzyme-linked immunosorbent assay) and a positive serotonin release assay.

Patients readmitted with thrombotic syndromes were treated with heparin, and those who subsequently experienced a significant drop in platelet count had both positive heparin-PF4 antibodies and a positive serotonin release assay. Connecting the dots in the platelet count patterns depicting the patients displayed in figure 2 of the Catalano report, the patterns are then reminiscent of the abnormal patterns in of post-CPB HIT patients depicted in the

\footnotetext{
From the ${ }^{\mathrm{a}}$ Division of Cardiovascular Surgery and ${ }^{\mathrm{b}}$ Department of Pathology, Maine Medical Center, Portland, Me.

Disclosures: The authors reported no conflicts of interest.

The Journal policy requires editors and reviewers to disclose conflicts of interest and to decline handling or reviewing manuscripts for which they may have a conflict of interest. The editors and reviewers of this article have no conflicts of interest.

Received for publication Aug 12, 2020; revisions received Aug 12, 2020; accepted for publication Aug 21, 2020; available ahead of print Sept 17, 2020.

Address for reprints: Robert S. Kramer, MD, Division of Cardiovascular Surgery,

Maine Medical Center, 22 Bramhall St, Portland, ME 04102 (E-mail: kramer@

mmc.org).

JTCVS Open 2020;4:45-6

2666-2736

Copyright (C) 2020 The Authors. Published by Elsevier Inc. on behalf of The American Association for Thoracic Surgery. This is an open access article under the CC BY-NCND license (http://creativecommons.org/licenses/by-nc-nd/4.0/).

https://doi.org/10.1016/j.xjon.2020.08.015
}

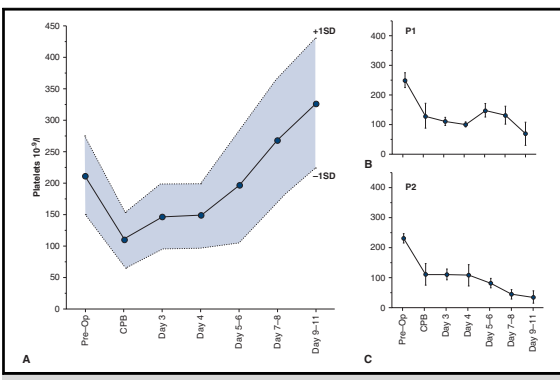

A, Normal changes in platelet count post-cardiopulmonary bypass. B and C, Changes in platelet counts in heparin-induced thrombocytopenia (Reprinted with permission.')

\section{CENTRAL MESSAGE}

The post-cardiopulmonary

bypass platelet count pattern in

heparin-induced thrombocyto-

penia (HIT) is similar in patients

readmitted with delayed $\mathrm{HIT/}$

heparin-induced thrombocyto-

penia and thrombosis syndrome.

Avoid heparin until HIT is ruled

out, even if they are not

thrombocytopenic.

central image reported by Pouplard and colleagues. ${ }^{1}$ In the cohort of Catalano and colleagues, because of the delayed onset, the pattern is stretched out over a longer time period. The patients of Catalano and colleagues started with a post-CPB drop and then exhibited a degree of recovery similar to that seen in Pouplard and colleagues' panel A. On readmission, the platelet count fell (exacerbated by the administration of heparin) similar to the patterns in Pouplard and colleagues' panel B or C. It is important to note that the patients who ultimately tested positive both immunologically and functionally for HIT presented with normal platelet counts, emphasizing the fact that thrombocytopenia is not a sensitive indicator of HIT.

Catalano and colleagues have reported on an important manifestation of delayed HIT/HITTS, with late presentations of this disorder in readmitted patients. At the time of readmission, patients who had thrombotic complications included those with deep venous thrombosis, pulmonary embolus, and mesenteric ischemia. Are there more prothrombotic patients with HITTS who are undiagnosed? 
The patients in this series made it back to the hospital, whereas others may have stayed home and survived (or not) with DVT, graft failure, pulmonary emboli, and other prothrombotic events.

Evaluation of this case series of Catalano and colleagues emphasizes that a thrombotic postoperative event is a potential indicator for HITTS during readmission even in the absence of thrombocytopenia. ${ }^{3}$ Furthermore, provoking these patients with heparin worsens the situation, as demonstrated in this case series, in which the thrombocytopenia (and likely the thrombosis) was exacerbated by the administration of heparin. Alternative anticoagulants to heparin should be used pending a more definitive diag- nosis. By telling us this valuable story, Catalano and colleagues have increased our awareness of the potential for HITTS in this setting, to look for it even in the absence of thrombocytopenia, and to avoid heparin until HITTS is ruled out.

\section{References}

1. Pouplard C, May MA, Regina S. Changes in platelet count after cardiac surgery can effectively predict the development of pathogenic heparin-dependent antibodies. Br J Haematol. 2005;128:837-41.

2. Warkentin TE, Kelton JG. Delayed-onset heparin-induced thrombocytopenia and thrombosis. Ann Intern Med. 2001;135:502-6.

3. Catalano MA, Prasad V, Spring AM, Cassiere H, Chang TY, Hartman A, et al. Heparin-induced thrombocytopenia in patients readmitted after open cardiac surgical procedures: a case series. J Thorac Cardiovasc Surg Open. 2020;4:36-42. 